\title{
Da Genealogia da Moral à Moral do Ressentimento: A Crueldade nos Bons Costumes
}

From the genealogy of the moral to the moral of the resentment:The cruelty in the bad habits
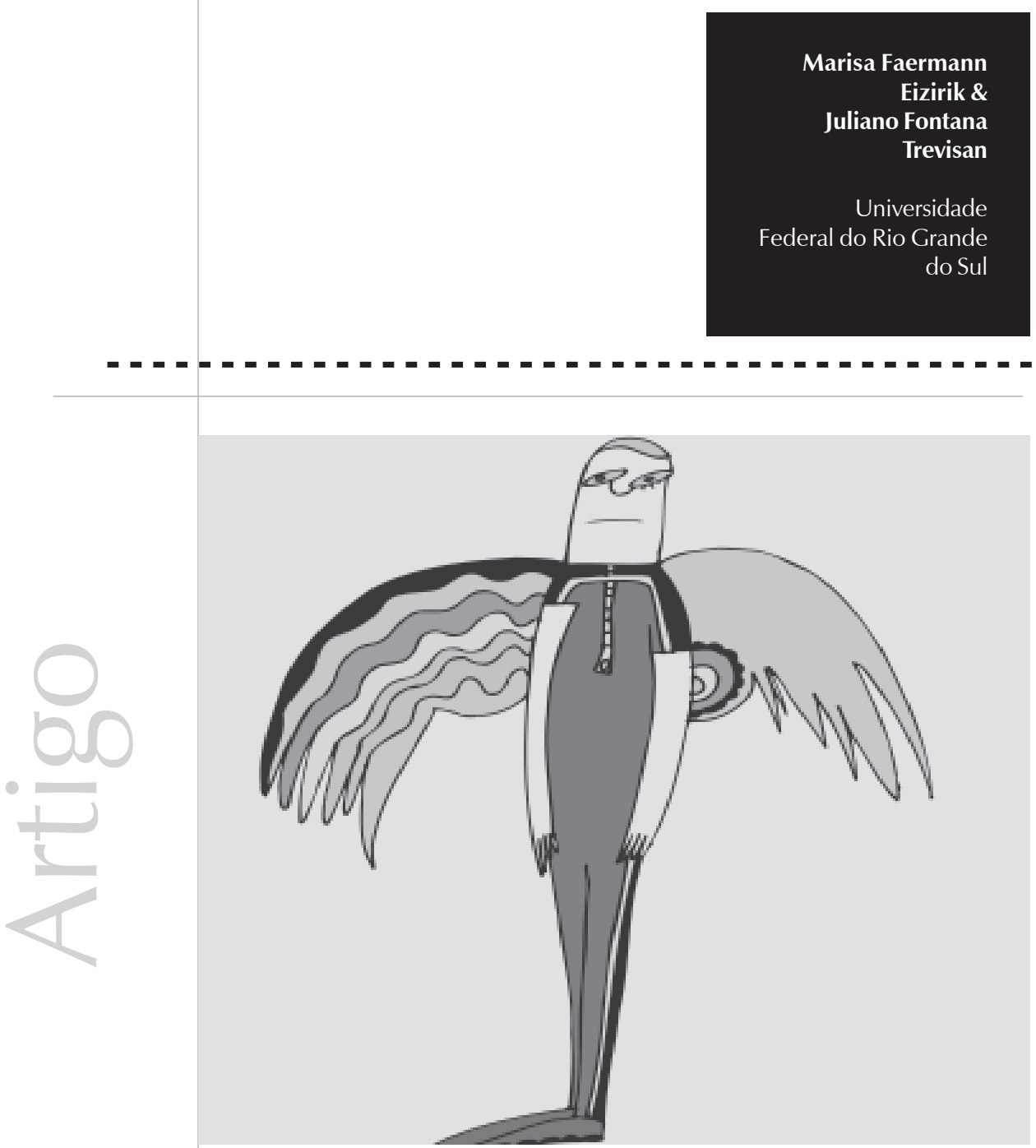


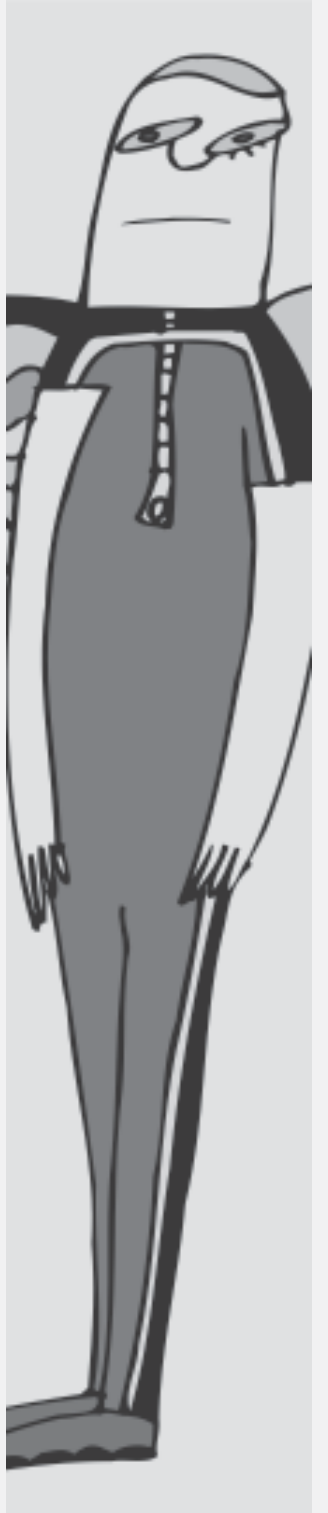

Resumo: Vivemos em um momento histórico em que a crueldade de algumas ações humanas (interpretadas como violentas e despidas de qualquer amor ao próximo) parece atingir um ápice, transformando-se em freqüentes matérias jornalísticas. Paralelo a essa realidade, cria-se o 'homem mau'; por contraste, surge o 'homem bom' (que não é capaz de cometer aquelas ações). A partir da reflexão sobre a idéia nietzscheana de genealogia da moral e sobre seu conceito de crueldade, esperamos, em um primeiro momento, problematizar não somente o 'homem mau' mas também o 'homem bom', com o intuito de pensar não sobre suas estruturas de personalidade, mas sim, sobre as condições histórico-sociais que possibilitaram a emergência desses dois tipos de homem, e, em um segundo momento, pensar a crueldade humana a partir de uma perspectiva histórica, contribuindo para um olhar sobre o humano que seja menos dicotômico e mais social, político e trágico.

Palavras-chave: Nietzsche, crueldade, moral, 'homem mau x homem bom'

Abstract: We live in an age in which the cruelty of some human actions (interpreted as violent and stripped of any love to others) seems to hit the apex, grading frequent journalistic subjects. Beside this reality, the 'bad man' is created; by contrast, it arises the 'good man' (who is not able to commit those actions). After the reflection about the nietzschean idea of the genealogy of the moral and about his concept of cruelty, we hope, in a first moment, to question not only about the 'bad man' but also about the 'good man', aiming to think not only about his or her personality structures, but about the sociohistorical conditions that enabled the emergence of these two sorts of man, and, in a second moment, to think about human cruelty from a historical perspective, contributing to a view about the human being that is less dicotomic and more social, political and tragic.

Key words: Nietzsche, cruelty, moral, 'bad man x good man'.

O número de assaltos, assassinatos, roubos, furtos (diariamente apresentados a partir dos mais diversos meios de comunicação) parece aumentar a cada dia. Uma certa insegurança toma conta de todos nós nos dias atuais. Temos medo do homem que, muitas vezes, mais nos parece um monstro horrível capaz de matar por um motivo fútil. Cria-se, portanto, uma dicotomia entre aquele que é capaz de matar (que é uma espécie de aberração humana) e aquele que não mata (o homem bondoso).
Temos por objetivo - a partir do levantamento das principais questões presentes em Nietzsche (1998) - analisar o conceito de crueldade e suas diversas formas de usos hoje em dia bem como suas diferentes valorações, ou seja, problematizar tanto aquele 'homem-mostro' capaz de matar quanto o 'homem bondoso', incapaz de fazê-lo.

Será que o 'homem-monstro' é mais cruel que o 'homem-bondoso'? Essa questão tem o 
interesse de problematizar esses 'tipos de homem' que, vistos dessa forma, muitas vezes acabam sendo vítimas de preconceitos sociais a partir da dicotomização. É uma questão, portanto, de inclusão social.

Com essa reflexão, esperamos contribuir indiretamente para a psicologia do ressentimento ${ }^{1}$, ou seja, para um tema candente em Nietzsche (1998), mas ainda pouco estudado ${ }^{2}$.

No livro Genealogia da Moral (Nietzsche, 1998), mais especificamente, na primeira das três dissertações que compõem o livro, vemos desenhar-se a constituição de estirpes. Duas morais são ali postas em evidência: a moral nobre e a moral dos escravos, ou, como Nietzsche mesmo chamou no título, "bom e mau", "bom e ruim". Essa diferenciação é crucial para nosso trabalho, pois, a todo o momento, falaremos de valores, de morais, enfim, de tipos de homem. Enquanto Nietzsche nos apresenta sua renovada tese para a genealogia da moral na primeira das três dissertações que compõem esse livro, a segunda dissertação vai dedicar-se ao estudo da culpa e das suas relações com a consciência, enquanto uma produção sóciomoral a partir de um momento onde se tornou possível "um animal que pode fazer promessas" (Nietzsche, 1998, p.47). E acrescenta : "Esta é a longa história da origem da responsabilidade. A tarefa de criar um animal capaz de fazer promessas, já percebemos, traz consigo, como condição e preparação, a tarefa mais imediata de tornar o homem até certo ponto necessário, uniforme, igual entre iguais, constante, e, portanto, confiável" (Nietzsche, 1998, p.48). A terceira dissertação vai tratar dos ideais ascéticos, ou seja, da ascensão da moral escrava no século XIX e da sua vitória parcial sobre a moral nobre: "no fato de o ideal ascético haver significado tanto para o homem se expressa o dado fundamental da vontade humana, o seu horror ao vácuo: ele precisa de um objetivo - e preferirá ainda querer o nada a nada querer. - Compreendem?... Fui
compreendido?..."Absolutamente não, Senhor!"- Então comecemos do início" (Nietzsche, 1998, pp.87-88).

Não foi pouco o empreendimento nietzscheano nesse livro (Nietzsche, 1998), que imaginamos poder ser considerado aquele que traz as idéias a respeito da genealogia da moral de forma mais clara e consistente a partir da intersecção de campos de conhecimento, como a Filosofia, a Psicologia, a fisiologia e a filologia, sendo este último de grande importância. Também é um livro singular quanto à "psicologia do ressentimento", descortinada minuciosamente na primeira das três dissertações desse livro.

Na primeira dissertação de Genealogia da Moral, vemos travar-se um duelo entre Nietzsche e os psicólogos ingleses quanto à gênese da moral. Estes, com a seguinte teoria: "Originalmente - assim eles decretam - as ações não egoístas foram louvadas e consideradas boas por aqueles aos quais eram feitas, aqueles aos quais eram úteis; mais tarde, foi esquecida essa origem do louvor, e as ações não egoístas, pelo simples fato de terem sido costumeiramente tidas como boas, foram também sentidas como boas - como se em si fossem algo bom" (Nietzsche, 1998, p. 18).

Para Nietzsche, essa teoria, além de a-histórica, sofre de um contra-senso psicológico, o que a tornaria insustentável: "A utilidade da ação não egoísta seria a causa da sua aprovação, e essa causa teria sido esquecida - como é possível tal esquecimento? A utilidade dessas ações teria deixado de existir? Ao contrário: essa utilidade foi experiência cotidiana em todas as épocas, portanto algo continuamente enfatizado; logo, em vez de desaparecer da consciência, em vez de tornar-se olvidável, deveria firmar-se na consciência com nitidez sempre maior. Bem mais razoável é a teoria oposta (nem por isso mais verdadeira), defendida por Herbert Spencer, por exemplo, que estabelece o conceito "bom" como essencialmente igual a "útil", "conveniente", de modo que, nos conceitos "bom" e "ruim", a humanidade teria sumariado 
e sancionado justamente as suas experiências inesquecidas e inesquecíveis acerca do útilconveniente e do nocivo-inconveniente. Bom é, segundo essa teoria, o que desde sempre demonstrou ser útil..." (Nietzsche,1998, p.20). O trecho é longo e importante para nossos próximos passos, pois, a partir daí, ficará mais clara a compreensão do encaminhamento que Nietzsche dá a essa questão da genealogia da moral.

A partir do exposto acima, pode-se ter a certeza de que as duas concepções utilizam para sua argumentação as palavras esquecimento e utilidade. No primeiro caso, a utilidade faz esquecer que ela - a utilidade - está na raiz da constituição do 'bom', e, no segundo caso, a utilidade torna inesquecível - sanciona aquilo que sempre demonstrou ser útilconveniente. Ora, liga-se o útil ao bom como se essa ligação fosse verdadeira em si, algo natural, e acrescenta-se aí um esquecimento dessa ligação, quando a mesma seria reiteradamente repetida, - como é possível tal esquecimento? Ambas as teorias buscam explicações para o surgimento dos valores tomando alguns valores a priori, pois útil e bom estiveram sempre ligados, necessariamente? A contribuição nietzscheana vem auxiliar-nos no sentido de mostrar que essas teorias são muito simplistas, que não levam o assunto com a seriedade e a profundidade que o mesmo requer.

A partir de uma análise filológica e, mais especificamente, etimológica, Nietzsche nos mostra outros caminhos para um conhecimento mais sério desse tema. Parte da seguinte questão: "que significam exatamente, do ponto de vista etimológico, as designações para "bom" cunhadas pelas diversas línguas? Descobri então que todas elas remetem à mesma transformação conceitual - que, em toda parte, "nobre", "aristocrático", no sentido social, é o conceito básico a partir do qual necessariamente se desenvolveu "bom", no sentido de "espiritualmente nobre", "aristocrático", de "espiritualmente bemnascido", "espiritualmente privilegiado": um desenvolvimento que sempre corre paralelo àquele outro que faz "plebeu", "comum", "baixo" transmutar-se finalmente em "ruim" (Nietzsche, 1998, p.21).

Vemos aqui que o surgimento do "bom" não está ligado ao esquecimento da utilidade, ou mecanização por repetição do útil-conveniente, não! Chamamos a atenção para o fato de que, etimologicamente, "bom" surge de "nobre", "aristocrático", marcando claramente aqueles que são "espiritualmente bem nascidos", "espiritualmente privilegiados". Ele não é esquecido nem reiterado, mas sim, criado para marcar uma diferença, para marcar um privilégio. Pergunta: o que essa marcação de privilégios - característica da estirpe nobre tem a ver com a utilidade para a qual a ação é direcionada?

Nietzsche vai mostrando, ao longo dessa primeira dissertação, a ligação etimológica das palavras "bom, nobre", que significam também alguém que é, que tem realidade, que é real, verdadeiro. Já as palavras "mau, feio", como tímido, covarde, homem comum, pele escura, plebeu (Nietzsche, 1998, p.22).

"Acredito poder interpretar o latim bonus como 'o guerreiro', desde que esteja certo ao derivar bonus de um mais antigo duonus (compare-se belum = duelum = duen-lum, no qual me parece conservado o duonus). Bonus, portanto, como homem da disputa, da dissensão (duo), como o guerreiro: percebe-se o que, na Roma antiga, constituía a "bondade" de um homem" (Nietzsche, 1998, p.23).

Quanta diferença para o nosso "bom" de hoje, um homem cada vez mais pacífico, covarde, pelo menos para os olhos da Roma antiga, pois o que realmente percebemos é uma guerra invisível, uma guerra de adestramento, uma guerra do homem contra o próprio homem. Chamamos a esse último homem de homem civilizado, humano, superior aos animais. Logo se percebe que o reino de moral é de longe, bem longe, o reino da verdade. Não nos iludamos com os "bons" que existem por aí, pois não há nada de verdade em sua volta.
Vemos aqui que o surgimento do "bom" não está ligado ao esquecimento da utilidade, ou mecanização por repetição do útilconveniente, não! Chamamos a atenção para o fato de que, etimologicamente, "bom" surge de "nobre", "aristocrático", marcando claramente aqueles que são "espiritualmente bem nascidos", "espiritualmente privilegiados". 
Essa inversão do olhar que estabelece valores - esse necessário dirigir-se para fora, em vez de voltarse para si - é algo próprio do ressentimento: a moral escrava sempre requer, para nascer, um mundo oposto e exterior, para poder agir em absoluto - sua ação é, no fundo, reação.
"Assim convinha a um povo sacerdotal, o povo da mais entranhada sede de vingança sacerdotal. Foram os judeus que, com apavorante coerência, ousaram inverter a equação de valores aristocrática (bom = nobre $=$ poderoso $=$ belo $=$ feliz $=$ caro aos deuses), e com unhas e dentes (os dentes do ódio mais fundo, o ódio impotente) apegaram-se a essa inversão, a saber, 'os miseráveis somente são bons, apenas os pobres, impotentes, baixos, são bons, os sofredores, necessitados, feios, doentes, são os únicos beatos, os únicos abençoados; unicamente para eles há bem-aventurança- mas vocês, nobres e poderosos, vocês serão por toda a eternidade os maus, os cruéis, os lascivos, os insaciáveis, os ímpios, serão também eternamente os desventurados, malditos e danados!...'" (Nietzsche, 1998, p. 26).

Isso é o que podemos chamar de uma verdadeira transvaloração dos valores, uma verdadeira inversão de valores, uma retomada de virtudes, onde o que era "bom" passa a ser "mau" e viceversa.

Nessa passagem, vemos claramente o surgimento de toda uma gama de valores sacerdotais, cristãos, que possuímos ainda hoje, de forma ativa sobre nossas vidas, produzindo pensamentos e sentimentos, sonhos e esperanças, missas, cultos e revoluções subjetivas.

"A rebelião escrava na moral começa quando o próprio ressentimento se torna criador e gera valores: o ressentimento dos seres aos quais é negada a verdadeira reação, a dos atos, e que apenas por uma vingança imaginária obtêm reparação. Enquanto toda moral nobre nasce de um triunfante Sim a si mesma, já de início, a moral escrava diz Não a um "fora", um "outro", um "não-eu" - e esse Não é seu ato criador. Essa inversão do olhar que estabelece valores - esse necessário dirigir-se para fora, em vez de voltar-se para si - é algo próprio do ressentimento: a moral escrava sempre requer, para nascer, um mundo oposto e exterior, para poder agir em absoluto - sua ação é, no fundo, reação. $O$ contrário sucede no modo de valoração nobre: ele age e cresce espontaneamente, busca seu oposto apenas para dizer Sim a si mesmo com ainda maior júbilo e gratidão - seu conceito negativo, o "baixo", "comum", "ruim", é apenas uma imagem de contraste, pálida e posterior..." (Nietzsche, 1998, pp. 28-29).

Chegamos a um ponto fundamental, aquele que merece todos os esclarecimentos a fim de que possamos ser entendidos mais à frente quanto às nossas considerações sobre a psicologia do ressentimento.

Nietzsche não está aqui simplesmente caracterizando duas morais, mas sim, duas maneiras (mecanismos) pelos quais uma moral pode nascer, crescer, desenvolver-se. E isso é bastante importante! A moral nobre e a moral escrava.

Faremos um breve esquema para visualizarmos melhor a proposição nietzscheana e aquela com a qual trabalharemos:

\section{Moral nobre:}

\begin{tabular}{|l|l|l|}
\hline Moral nobre & "bom" & "ruim" \\
\hline Escolha & Primário & Secundário \\
\hline Afirmado por & É posterior, nasce por uma \\
\hline uma ação. & diferença, por uma distância \\
& daquilo que é bom. Não é \\
& negado, mas desprezado \\
& por não ser importante. \\
\hline
\end{tabular}


Moral escrava:

\begin{tabular}{|l|l|l|}
\hline Moral escrava & "mau" & "bom" \\
\hline Escolha & Primário & Secundário \\
\hline & Negado & Afirmado por uma reação. \\
& $\begin{array}{l}\text { Primeiro vem a negação } \\
\text { do que não é eu. }\end{array}$ & $\begin{array}{l}\text { O bom é tudo que não é "mau", por } \\
\text { exclusão. É o que sobra. É por oposição } \\
\text { que eu afirmo que sou "bom". }\end{array}$ \\
\hline
\end{tabular}

Essas duas tabelas mostram, como dissemos anteriormente, não duas morais, mas dois modos de construção de valores. Logicamente ninguém é só uma coisa ou só outra, tampouco representam estruturas de personalidade com prescrições de comportamentos, mas como pesos diferentes de uma balança que, por vezes, pode pesar mais para um lado ou para o outro. De qualquer forma, a segunda tabela, a segunda forma de criação de valores, retrata muito bem o mecanismo que dá à luz o ressentimento. Na verdade, o ressentimento, aquela vingança imaginária lenta e odiosa contra o mundo externo, é o propulsor da moral escrava. O que eu não gosto acaba definindo, por exclusão, pela força do ressentimento, o que me serve, o que é o meu "bom".

Na moral nobre, temos o "bom", de um lado, e o "ruim", do outro; já na moral escrava, a 'oposição' é entre "bom" e "mau". Certamente não se trata de palavras diferentes com o mesmo sentido, tampouco um descuido dos autores. Na moral nobre, o "bom" é escolhido em um ato, numa ação, algo como um apontamento daquilo que serve dentre tudo aquilo que se oferece como possibilidade, um ato afirmativo, portanto! $\mathrm{O}$ que é o "ruim"? Bem, o "ruim" é tudo aquilo que não fez parte da minha afirmação anterior, aquilo que está separado por uma distância dela, aquilo que ficou de fora do meu campo de interesse, aquilo que não enxergo, que nem sei da existência simplesmente porque não é importante para mim, e, por isso mesmo, é desprezado, e não negado, sempre lembrando que esse "ruim" só existe pela distância com relação àquilo que é - ao que eu disse Sim! Já na moral escrava, temos o "bom" e o "mau".
Aqui a história é outra, e bem mais conhecida por nós. Primeiramente escolhemos aquilo que Não nos serve, aquilo que nos causa raiva, ódio, aquilo que desperta em nós um forte desejo de vingança e que nos faz ruminar por muito e muito tempo antes de tomarmos alguma decisão. Por um ato de negação, portanto, afirmamos o que não nos serve, e este é o "mau". Em um segundo movimento, adotamos o que sobrou, por oposição ao que não serve, para ser o nosso "bom", um ato reativo, portanto! É por reação ao que não serve que estipulo o que me serve, é o que sobra, o pouco, o resto. Toda ação, aqui, é pautada em função do "fora", se faço ou não faço alguma coisa, se escolho esse ou aquele caminho, se me comporto dessa ou daquela maneira, enfim, tudo isso será medido por exclusão daquilo que, a priori, não me serve. A ação é uma reação, logo, ressentida, amarga, venenosa, grudenta. $\mathrm{O}$ "mau" não pode, aqui, ser desprezado, pois ele é mesmo mais importante que o "bom", ele vem antes, antecede a este, ele define o "bom". A vingança ressentida precisa de tempo, é estratégica, manhosa, mimada, provoca cansaço e, por fim, torpor. Envenena de tal forma a consciência que ela, ao invés de paralisar, agita-se compulsivamente em uma infinita excitação pelo justo, pelo correto, pelo belo, pelo não pecaminoso, pelo "fora". O caminho da ação sofre uma dobra e torna-se um " $U$ ", a retidão amolece ${ }^{3}$ e dificulta o escape, o homem torna-se tortuoso e obscuro para si mesmo, torna-se pecador em sua própria casa.

Portanto, a diferença entre nobre e escravo proposta por Nietzsche, bem como a sua genealogia da moral, traz uma outra importante
30 amolecimento do homem moderno é um tema constante em Nietzsche. Refere-se ao homem do ressentimento, o homem acuado em sua própria jaula, que ele mesmo construiu para a ele mesmo adestrar. Haveria coisa mais escrava que essa, ou seja, machucar-se (produzir sofrimento) contra as grades de uma jaula que nós mesmos construímos para nós mesmos vivermos nela? Em um lugar assim, dificil de viver, é bem possivel que "o senhor esteja convosco". "Sim", responde o bichinho enjaulado, "ele está no meio de nós". Nessa pequena morada dos pecadores, dar graças ao senhor, nosso Deus - "é nosso dever e nossa salvação". Para um morador de uma pequena jaula, humilde e pecador, essa salvação (divina) parece ser bastante condizente, e atélouvável. 
"Oh, quanta supérflua crueldade e tortura animal teve origem nas religióes que inventaramo pecado! E nos homens que quiseram, com isso, ter a mais alta fruição de seu poder!" (Nietzsche, 2004, p.46). contribuição. Ao contrário dos genealogistas ingleses, que acreditavam em uma explicação para o surgimento dos valores morais baseada no esquecimento e na utilidade, Nietzsche propõe uma outra genealogia baseada em seus estudos filológicos a partir da análise etimológica do valor "bom" em diferentes culturas. Fica claro que o "bom" sempre esteve ligado a nobre, aristocrático, àquele privilegiado. Logo, Nietzsche conclui que o "bom" (para os representantes da moral nobre) fora criado como forma de expansão do poder, aumento dos seus domínios sobre os escravos e, mais que isso, como forma de marcar lingüisticamente uma diferença entre aquilo que servia para si e aquilo que ficava fora dos interesses. Assim convinha agir aos nobres e aristocratas. Vemos que, nessa teoria, desaparecem aquelas explicações mágicas anteriores, e aparece uma explicação menos cristã e mais cruel. De fato, não é por amor ao próximo que o "bom" surge, como bem vimos anteriormente, mas por um ato de crueldade, um ato, para os nossos olhos atuais, desumano, animalesco.

É a vontade de poder que leva o nobre a criar o "bom" relacionando-o a tudo aquilo que Ihe serve, que o fortalece. A sua vontade soberana, o seu instinto cruel, aparecem, aqui, sem nenhuma vergonha. É esse o sentido da vida, criar o seu próprio "bom", sendo o "ruim" um reflexo, aquilo que fica fora dos meus interesses, aquilo que não desperta qualquer desejo no nobre, e portanto, é como se não existisse.

A teoria nietzscheana sobre a genealogia da moral tem, na sua raiz, a crueldade como força criadora de valores. Entretanto, engana-se quem pensa que a crueldade se encontre somente na origem da moral nobre. A grande contribuição nietzscheana é justamente mostrar a crueldade onde menos se esperaria encontrá-la, onde o humano (com sua alta capacidade intelectual e racional para predizer e fazer o "bem") parece prevalecer. Logo, "quando se fala de humanidade, a noção fundamental é a de algo que separa e distingue o homem da natureza. Mas uma tal separação não existe na realidade: as qualidades "naturais" e as propriamente chamadas "humanas" cresceram conjuntamente. O ser humano, em suas mais elevadas e nobres capacidades, é totalmente natureza, carregando consigo seu inquietante duplo caráter. As capacidades terríveis do homem, consideradas desumanas, talvez constituam o solo frutífero de onde pode brotar toda humanidade, em ímpetos, feitos e obras" (Nietzsche, 2000, p.65).

Logo se vê onde Nietzsche pretende chegar. "Oh, quanta supérflua crueldade e tortura animal teve origem nas religiões que inventaram o pecado! E nos homens que quiseram, com isso, ter a mais alta fruição de seu poder!" (Nietzsche, 2004, p.46).

De forma forte e decisiva, Nietzsche acrescenta que "de tudo isso resulta que a humanidade ainda se comporta, ante a morte na fogueira, as torturas e instrumentos de torturas espirituais, com a mesma angustiada paciência e indecisão de outrora ante as crueldades infligidas nos corpos de homens e animais" (Nietzsche, 2004, p.60).

Como vemos, a crueldade sempre esteve presente, até mesmo em práticas - refiro-me a práticas de todo tipo, tanto físicas (torturas corporais) quanto espirituais e psíquicas (torturas por responsabilidades, culpas, pecados, purgatório, etc.) - consideradas humanas e acima de qualquer suspeita, aliás, muitas delas com a aprovação 'divina'.

Imaginamos - para não sofrermos de máconsciência - que nossas atitudes altruístas, que tendem na direção da ajuda do outro, são exemplos magnânimos de doação nossa, embora representem o seu oposto. Também nas atitudes ditas de compaixão pelo outro vemos a expressão da crueldade na sua busca incessante de fruição do poder, ou seja, é na ajuda ao outro, na concessão do perdão, que atualizo minha vontade de poder, que me apresento como um superior, um tal que ainda tem algo para dar a um fracote, a um pecador, 
a um ressentido. Aquele sentimentozinho ${ }^{4}$ que sentimos ao ajudar os outros que necessitam, aquele prazerzinho ignóbil que enrijece e purifica nosso corpo tem aí a sua origem. Por longo tempo buscamos explicações "no outro" para nossos prazeres e desprazeres, como se uma ação em si mesma produzisse bem-estar (como, por longo tempo, pensamos a respeito das experiências filantrópicas), mas esperamos estar trazendo uma nova visão, a partir de Nietzsche, que depõe contra essa teoria da naturalidade de alguns sentimentos, uma tal que pouco carrega da noção de humano hoje presente.

Nobre e escravo apresentam, portanto, nas bases de suas constituições, a crueldade inexoravelmente, pois, como vimos, não só a crueldade, mas também a necessidade de crueldade sempre acompanharam o homem. A diferença é que, enquanto aquele vê, na sua crueldade, um motivo para festa e comemoração (e são vários os exemplos em que Nietzsche mostra certas culturas que não conseguem conceber uma festa sem sacrifício, sem sofrimento, sem torturas) este se envergonha disso, envergonha-se do seu parentesco com os animais, envergonha-se do seu inumano e, na tentativa de negá-lo (de negar esse nojo, náusea consigo mesmo), direciona-o contra si próprio, criando uma série de instrumentos de tortura, como a penitência, o pecado, a culpa, o ressentimento, enfim, deixa de ser digno em sua própria morada, passando a desprezar a si e à vida com um contundente Não. Essa negação, portanto, passa a ser o princípio de tudo, o centro gravitacional que produz valores, os "maus" e os "bons" costumes.

Será que o 'homem-monstro' é mais cruel que o 'homem bondoso'? Se levarmos em conta que não era nosso objetivo encontrar uma resposta para essa questão (ou seja, dizer qual deles seria o mais feio, ou o mais nobre), por outro lado, esperamos que a resposta a ela tampouco seja dada de forma automática, como, muitas vezes, somos moralmente impelidos a pronunciar.
4 As palavras presentes nessa frase, no diminutivo, têm por objetivo marcar que o prazer sentido em ações que visam - pois assim são chamadas - 'ao próximo' apresentam um objetivo que é o mesmo alcançado por outros meios ditos mais 'egoistas'; entretanto, enquanto nestes a ação é direta e evidente tanto em relação aos seus meios como aos seus fins, naquele, os atos para alcançar o mesmo fim (exercícios de expansão e fruição de seu poder e, em conseqüencia, de domínio sobre o outro) são mascarados e indiretos; a ação percorre um caminho maior e mais tortuoso antes de tornar-se uma prática propriamente dita, o que a desfigura quase que completamente parecendo, ao fim, uma ação "ao outro" num complexo engenhamento e obscurecimento da crueldade e do exercicio de poder, visto agora como algo vergonhoso. A idéia de 'sentimentozinho' é para marcar esse sentimento experimentado após essa transvaloração dos valores.

Recebido 06/10/05 Reformulado 13/04/06 Aprovado 02/06/06

Psicólogo, formado pela UFSM; Mestre em Psicologia Social e Institucional/UFRCS; Professor do Curso de Psicologia da Universidade Regional Integrada do Alto Uruguai e das Missões / URI-Santiago. José Gabriel Brenner, 450. Bairro Tancredo Neves - CEP 97032-240 - Santa Maria, RS. E-mail: psicologo_jft@yahoo.com.br

Doutora em Educação, UFRGS, professora do Curso de Pós-Graduação em Psicologia Social e Institucional/ UFRGS; Visconde do Rio Branco, 708 - CEP 90220-230 -Porto Alegre, RS. E-mail: meizirik.ez@terra.com.br

\section{Juliano Fontana Trevisan}

EIZIRIK, M. F.
Unijuí, 2002.

GIACOIA J., O. Nietzsche como Psicólogo. São Leopoldo: Unisinos, 2001.
NIETZSCHE, F. Aurora. São Paulo: Companhia das Letras, 2004. Cinco Prefácios para Cinco Livros não Escritos. Rio de Janeiro: Ed. 7 letras, 2000.

Genealogia da Moral. São Paulo: Companhia das Letras, 1998.
Referências 